\title{
Evaluation and Analysis of Risk Factors of Green Building Life Cycle
}

\author{
Jiao Lili \\ Yunnan College of Business Management, Yunnan,650304, China
}

Keywords: Green building life cycle evaluation system

\begin{abstract}
During the “Twelfth Five-Year Plan” period, the green building special content was included in the goal of scientific and technological development in the field of housing and urban and rural construction. At the same time, it also issued relevant policies that will clearly establish a financial incentive mechanism, improve standards and evaluation of the identification system, promote relevant scientific and technological progress and industrial development, and strive to achieve more than 30\% of new buildings by 2020. This paper first gives an overview of the green building life cycle assessment system. Through the analysis of the advantages of the life cycle assessment system, from the planning, planning, design, construction, operation and demolition stages, the green life cycle assessment strategy is proposed.
\end{abstract}

\section{Introduction}

Green buildings are the dominant trend in future buildings. In the period of large-scale construction of green buildings, there are currently "Green Building Evaluation Standards" and "Green Design Codes for Civil Buildings" as the basis for evaluating and determining the level of green buildings, but there is no comprehensive improvement from decision-making, planning, design, construction and operation. And the entire process of green building life cycle evaluation system. How to scientifically and reasonably measure the degree to which a building achieves "greenness" throughout its life cycle, and provide engineers with a simple and clear evaluation tool? This paper will conduct an in-depth analysis and discussion of the green building evaluation system based on the life cycle perspective.

\subsection{Green Building Life Cycle Assessment Concept}

Green building means maximizing resource conservation (energy saving, land saving, water saving, material saving), protecting the environment and reducing pollution during the whole life cycle of the building, providing people with healthy, applicable and efficient use of space and nature. Harmony of symbiotic buildings. The whole life cycle assessment of green buildings is a comprehensive evaluation of green buildings from "space" and "time". The whole process is evaluated in the stages of decision-making, planning, design, construction, operation management and demolition. Thereby achieving the scientific evaluation of green building evaluation. Among them, "time" reflects the whole process, including planning, planning, design, construction, operation management, and dismantling all the links in the whole process. "Space" reflects all aspects, from the aspects of land and outdoor environment, energy conservation and energy utilization, water and water use, material and material resource utilization, indoor environmental quality and operation management, and expands from the single energy consumption of buildings. A comprehensive review of the impact of construction activities on the surrounding ecological environment and the environment in which the occupants live.

\subsection{Green Building Life Cycle Assessment System}

The construction of a green building life cycle assessment system is a complex system engineering. Consider the main body, space, and time. Participants include government management departments, which are carefully checked and strictly managed during project approval, approval and daily management. The planning unit, from the early stage of implanting green building related concepts is the prerequisite for improving the level of green building 
construction. The design unit determines the main function and quality level of green building and is the key to achieving green building. The construction unit has a great impact on the surrounding environment, so it is necessary to formulate corresponding measures. The operation management unit must adopt a scientific management method, establish a reasonable management system, and use modern management methods for scientific management. The green building consulting service unit has a significant impact on the implementation of green buildings. "Time" is divided into detailed stages according to each subject, including decision-making, planning, design, construction, operation, and demolition stages. "Space" achieves land and outdoor environment, energy conservation and energy utilization, water and water use, material and material utilization, indoor environmental quality and operational management for all phases of time.

From the perspective of the life cycle of the building, green buildings can build a safe, healthy, efficient and comfortable environment under environmental load through reasonable resource conservation and efficient use, and realize the symbiosis and sustainable development of people, environment and architecture. It will fully meet the four goals of "energy saving, land saving, water saving, material saving”, environmental protection (protecting the natural environment and resources, and ensuring the quality of indoor and outdoor buildings).

\section{Advantages of the green building life cycle evaluation system}

The whole life cycle assessment of green buildings is based on the whole, tailor-made for the project, from the planning, planning, design, construction, operation, and demolition process, we must implement the low-cost and low-cost concept of green buildings. The green building life cycle assessment system has the following advantages:

(1) Comprehensive evaluation of green buildings from the perspective of time, space, and participation. The comprehensiveness, integrity and systemization of the evaluation system have been realized.

(2) The problems of each link can be found in time to take timely measures to rectify and meet the evaluation criteria of green buildings. Not only can the overall goal be controlled, but the cost can be kept to a minimum.

(3) It is conducive to clear responsibility of each participating entity. Make relevant users use relevant evaluation methods conveniently and quickly. Improve work efficiency.

(4) The green building life cycle assessment system can form a closed cycle of the green building life cycle[1].The key factors of the building are as follows.

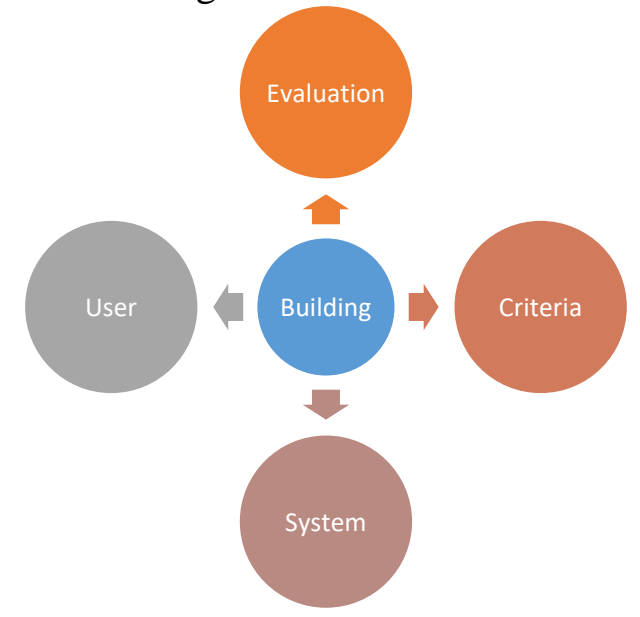

Figure 1: Key factors of the building

\section{Green building life cycle evaluation system strategy}

\subsection{Decision stage}

After discovering the intention of germination from the construction unit and forming a general 
description of the project, it will proceed with the investigation and research, and consult with relevant departments. According to the characteristics of the project, determine the impact of the project on the environment, and comprehensively consider the energy consumption level, renewable energy utilization, spatial layout, structural design and material selection are conducive to energy conservation, from the early stage to achieve the option of the principle of minimum cost.

\subsection{Planning stage}

In the planning stage, we should pay attention to the deepening of the green concept, reduce the impact of unreasonable construction activities on the environment, and make the building and the environment continue to live in harmony. The achievement of this goal requires an evaluation of the existing infrastructure and building requirements of the planned land, existing natural topography, waters, water sources, ecosystems and biodiversity conservation, as well as review of the planning plan, and then adopt a scientific and systematic Planning method[2].

\subsection{Design stage}

The design phase is the process of embodying the quality objectives and levels determined in the decision-making phase, and is the decisive link in the quality of green building projects. It is the basis of construction and it must be ensured that the design meets the basic requirements of green buildings. The project after the design review is qualified enters the construction drawing review stage, and then the design plan is comprehensively evaluated.

Through the use of reasonable control of building size, floor area ratio and area, improve land use efficiency; improve the site's ecological environment, as well as outdoor sound, light, heat, wind and other indicators to investigate green buildings; use computer simulation tools to compare building windows Comprehensive optimization design of body shape coefficient, thermal insulation performance and lighting performance of heating structure, heating and air conditioning system, domestic hot water system, etc.; rational use of renewable energy, reduce pollution to the environment, achieve sustainable development; innovative use of new technology Collect and reuse resources.

\subsection{Construction stage}

The construction phase is the process of realizing the value and use value of green building projects according to the design drawings, which is essential for the implementation of the green building concept. Green construction implements the green concepts of "clean production" and "subtraction reduction", which is to innovate and upgrade the traditional construction system, with environmental impact control, energy conservation and water saving, personnel safety and health, etc. Comply with green and construction principles. In the completion and acceptance stage, it is necessary to examine the protection of the site's ecological environment, control noise, light pollution, construction mass, and air pollution to ensure that the green building design is truly implemented[3].

\subsection{Operational stage}

The operation phase is the longest phase in the life cycle of the building. After the building is put into use for one year, the green building evaluation is carried out to verify the implementation effect, and the national green building evaluation mark is applied. At this stage, effective green management is achieved through the design of effective management systems and incentives. For buildings that are innovative in the architectural design concept, adopting new technologies, new products, new materials and new processes, and at the same time, adapting to local conditions, and giving significant points and rewards in improving the ecological performance of the building[4].

\subsection{Demolition phase}

Since green building projects emphasize the recyclability of resources throughout the life cycle, detailed analysis is also required during the demolition phase to minimize environmental pollution and maximize resource recycling. During the demolition phase of the building, the building should 
be evaluated for post-green building, including the impact of migration, demolition, and the impact of retrofitting and reuse. Through green building post-evaluation, inform decision makers when they should make an updated investment in the current equipment to achieve the lowest energy consumption and lowest operating costs. Through comprehensive diagnosis of building performance, reasonable replacement of building materials and equipment systems, improvement of building durability and life, comprehensive renovation of energy-saving and water-saving buildings, rational planning of disassembly and replacement of building materials, and realization of resource utilization, avoiding Adverse effects of the environment[5].

\section{Conclusions}

The green building life cycle assessment system can not only control the overall control from a macro perspective, but also control it in stages to detect and solve problems in a timely manner. Improving the green building evaluation system can play an effective guiding role in the implementation of future green buildings. More importantly, the building can realize the full utilization of resources and energy, truly achieve the harmony between architecture and nature, environment and society, and promote the development of low-carbon cities in China.

\section{References}

[1] Yujie Lu, Zhilei Wu, Ruidong Chang, Yongkui Li. Building Information Modeling (BIM) for green buildings: A critical review and future directions[J]. Automation in Construction,2017,83.

[2] Harsha S. Fowdar, Belinda E. Hatt, Peter Breen, Perran L.M. Cook, Ana Deletic. Designing living walls for greywater treatment[J]. Water Research,2017,110.

[3] Cyril Sola, Bruno Castanié, Laurent Michel, Frédéric Lachaud, Arnaud Delabie, Emmanuel Mermoz. Bearing fatigue of composite laminates: Damage monitoring and fatigue life prediction[J]. Composites Part B,2017,110.

[4] Byung Kwan Oh, Se Woon Choi, Hyo Seon Park. Influence of variations in CO 2 emission data upon environmental impact of building construction[J]. Journal of Cleaner Production,2017,140.

[5] Harsha S. Fowdar, Belinda E. Hatt, Peter Breen, Perran L.M. Cook, Ana Deletic. Designing living walls for greywater treatment[J]. Water Research,2017,110. 